\title{
Ssciendo
}

Ethics \& Bioethics (in Central Europe), 2020, 10 (3-4), 221-229

DOI:10.2478/ebce-2020-0013

\section{Euthanasia as an issue in ethics of social consequences?}

\author{
Ján Kalajtzidis ${ }^{1}$
}

\begin{abstract}
The main aim of the presented paper is to look for an answer as to whether and how euthanasia reflected is in ethics of social consequences. Ethics of social consequences is a contemporary Slovak ethical theory with an original approach to delimitating moral agency. The paper puts this definition to the test while considering the main focus of the paper - responding to the question of whether euthanasia and end of life can be understood as a moral uncertainty. The intention is to find out whether the definition is clear and adequate to withstand the basic arguments against euthanasia. Since ethics of social consequences is a consequentialist ethical theory, another partial goal is to analyse the fitness of such a position to be used in bioethical inquires.
\end{abstract}

Keywords: euthanasia, moral agent, moral subject, ethics of social consequences

\section{Introduction}

Before we start our journey and look for the answers, which are of interest in the paper, first of all, it is necessary to find a definition of euthanasia which will fit our aims. There are many definitions of euthanasia from different areas of knowledge. We are not interested in a strictly legal or medical definition but much more in a philosophical-ethical definition which is based on the present understanding of the concept. That does not mean that those definitions cannot overlap. On the contrary, they are very much connected as (e.g.) a philosophical-ethical definition cannot ignore technological advances in the field of medicine. Subsequently, the legal definition should not ignore philosophical debate.

\section{The definition}

One of the first systematical attempts to find a such definition is a paper written by Tom Beauchamp \& Arnold Davidson. ${ }^{2}$ Their goal was to find a definition that could be nonprescriptive and would not be subject to refute by counterexample. As an illustration of such insufficient definitions, one which was favoured ${ }^{3}$ in the seventies is used: euthanasia is understood as "the painless inducement of a quick death". The weakness of this definition is very much clear, as it does not include (among other things) the elements of suffering or disease. Inducing a quick death on somebody who is not suffering would most probably be "just" murder. Another aspect which might be useful (maybe even necessary) is the element of a motive, which is closely connected to an aspect of beneficence. To overcome all of those and many other insufficiencies, Beauchamp and Davidson submitted a definition which is based on five conditions.

The death of a human being $\mathrm{A}$ is an instance of euthanasia if and only if:

(1) A's death is intended by at least one other human being (B), where B is either the cause of death or a causally relevant feature of the event resulting in death (whether by action or by omission);

(2) there is either sufficient current evidence for B to believe that A is acutely suffering or irreversibly comatose, or there is sufficient current evidence related to A's present condition such that one or more known causal laws supports B's belief that A will be in a condition of acute suffering or irreversible comatose;

\footnotetext{
${ }^{1}$ University of Prešov (Slovakia); jan.kalajtzidis@unipo.sk

${ }^{2}$ The paper is almost a half century old (1979).

${ }^{3}$ The definition was even included in the Oxford English Dictionary.
} 
(3) (a) B's primary reason for intending A's death is cessation of A's (actual or predicted future) suffering or irreversible comatose, where B does not intend A's death for a different primary reason, though there may be other relevant reasons, and (b) there is sufficient current evidence for either A or B that causal means to A's death will not produce any more suffering than would be produced for A if B were nor to intervene;

(4) the causal means to the event of A's death are chosen by A or B to be as painless as possible unless either A or B has an overriding reason for a more painful causal means, where the reason for choosing the latter causal means does not conflict with the evidence in $3 b$;

(5) A is a non-foetal organism (Beauchamp \& Davidson, 1979, p. 304).

With respect to the first condition of their definition, a narrower type of euthanasia exists physician-assisted suicide as one form of euthanasia (which has a wider meaning). According to Peter Singer, within the usual definition, there are three different types of euthanasia, ${ }^{4}$ from which each raises a distinctive ethical issue - voluntary, ${ }^{5}$ involuntary $^{6}$ and non-voluntary ${ }^{7}$ euthanasia. Even the case for voluntary and non-voluntary euthanasia has some common ground (benefit for the one killed/ not a harm) the two differ (Singer, 2011). In the terms of ethics of social consequences, voluntary euthanasia involves the killing of the moral subject/ human being (or the former moral subject who consented), while the non-voluntary form does not. Non-voluntary euthanasia involves the killing of a moral object who never was a moral subject, or, one which was a moral subject before, but as one, they did not give a clear answer on the question of euthanasia.

\section{Ethics of social consequences - introduction}

Ethics of social consequences can be characterised as a consequentialist ethical theory with the inclination to act according to utilitarianism and by adopting a case-oriented approach. The case-oriented approach is acknowledged as a better way of dealing with specific moral issues of everyday life. Other aspects of ethics of social consequences are moderate subjectivity, hedonism, and partial eudemonism. Even though this might signalize a certain similarity with utilitarianism, ethics of social consequences refuses to be associated with it. The core values of ethics of social consequences are humanity, human dignity, and moral right. Secondary, or auxiliary values closely interconnected with the primary ones are responsibility and justice.

The values which are closely connected with the issue of this paper are humanity ${ }^{8}$ and human dignity. They are understood in connection with the protection, support, and development of human life that usually bring positive social consequences. The theory assumes that protection and support of the development of life (including human life) bring positive social consequences. ${ }^{9}$ That is why people naturally tend to protect and support life in any form. The

\footnotetext{
${ }^{4}$ Singer defines the euthanasia as "the killing of those who are incurably ill and in great pain or distress, in order to spare them further suffering or distress" (Singer, 2011, p. 157).

${ }^{5}$ Euthanasia which is carried out at the voluntary request of the person killed, who must be, when making the request, mentally competent and adequately informed (Singer, 2011, p. 157).

${ }^{6}$ Euthanasia is defined by Singer as involuntary when the person killed is capable of consenting to their own death but does not do so. There are at least two reasons, either they does not do so because they are not asked or because they are asked and choose to go on living (Singer, 2011, p. 158).

${ }^{7}$ Singer refers to euthanasia as non-voluntary if a human being is not capable of understanding the choice between life and death and therefore is unable to give consent (without having previously requested or rejected euthanasia in these circumstances) (Singer, 2011, p. 158).

${ }^{8}$ Humanity is, in ethics of social consequences, expressed as respect for the human being per se (Gluchman, 2018, p. Xv).

${ }_{9}^{9}$ Positive social consequences can be characterized as consequences which help to satisfy the necessity of moral agents, social community or society as such. They are an essential condition (and at the same time part) of the good (Gluchman, 1994, p. 16; Gluchman, 1999, p. 18).
} 
reason is not only the awareness of our duty to act to produce positive social consequences but predominantly our compassion with suffering people and our need to help to protect and support life.

Gluchman states that every adult moral agent gains the value of human dignity as a human based on the fact of his/her existence. Nevertheless, the demand on the respect of his/her dignity and humanity in relation to him/herself must be permanently confirmed by his/her actions, more specifically by the character of his/her actions that should be in accordance with valid and acceptable moral norms (even legal norms to some point - e. g. the right to live) or, at least, should not be in contrast with them (Gluchman, 1997, p. 156). According to ethics of social consequences, every human being (even mentally disabled individuals) has the primary equivalent value of human dignity. When promoting the value of humanity, ethics of social consequences differentiates on the grounds of the qualitative criteria of human life. Realization of the value of humanity in ethics of social consequences can then bring us to a situation in which terminating the life of a constantly suffering being is a demonstration of humanity.

Dignity ${ }^{10}$ in ethics of social consequences is understood as a value that we assign to entities following a body of qualities or values they have and that are worthy of esteem and respect (Gluchman, 2008, pp. 92-93). All living entities have a certain basic degree of dignity with regard to their being. This is called the ontological grounds of the value in ethics of social consequences. However, the value is neither absolute nor constant. As already stated, it greatly depends on the stage of development of an entity and its activity. To be more terminologically clear, it is necessary at this point to distinguish between "to exist" and "to be" (to be alive). The being of the entity, so when an entity "is", means that he/she "lives" and because the entity "is" - lives, he/she has a basic degree of dignity. However, if the entity not only lives but additionally, he/she lives actively (is in interaction with its surroundings on a required level), then it can be stated that he/she exists. Death is considered as something bad (usually not desired) for several reasons. One of the most vigorous ones is the fact that death deprives us of the good things we would have enjoyed had we lived on (others might include fear of the unknown, or of pain during the process of dying, etc.). Of course, the former is true only under the assumption that we have the ability to enjoy the good. We have this ability only if we really exist as active beings, not only "are" living entities.

In ethics of social consequences, the actions and activities of existing beings are regarded as a criterion for the differentiation of the dignity which is ascribed to the entity. The dignity which is ascribed is different, on the one hand, from species to species (it depends on their developmental stage in the evolutionary chain), and as well between individuals from the same species (it depends on the consequences of their actions) (Gluchman, 2009, p. 83).

Ethics of social consequences works with categories that might make the issue we are dealing with in this paper much clearer. It distinguishes between the moral agent (subject) and the moral object. The term moral agent refers to beings, which are usually named as "real" human beings, as somebody who shows "true" human qualities. In Singer's words, this type of labelling does not refer to membership of the species (Homo sapiens), which is a biological fact, but it implies that beings "characteristically possess certain qualities, and this person possesses them to a high degree" (Singer, 2011, p. 73).

Gluchman states that a moral agent is an agent of morality fulfilling required criteria: "he/she is able to recognize and understand the existing moral status of society and is competent of conscious and voluntary activity, ${ }^{11}$ for which he/she needs to take moral responsibility"

\footnotetext{
${ }^{10}$ For a better understanding of the issue of dignity in the ethics of social consequences within the concept of dying look at the paper of Katarína Komenská (2018). Komenská states that dying with dignity might be an eligible answer to ethical dilemmas for those who cannot fulfil their goals and considers their life to be irreversibly bad and full of suffering.

${ }^{11}$ In other words, an agent must be a rational and self-conscious being.
} 
(Gluchman, 1997, p. 22; Gluchman, 2018, p. xv). ${ }^{12}$ If we break down this definition, the following is required from the agent: self-awareness, self-control, a sense of the future, a sense of the past, a capacity to relate to others, concern for others, communication and curiosity. ${ }^{13}$ Those are the conditions that an agent must fulfill in order to be able to take moral responsibility and therefore become a moral agent.

What is interesting in this definition is the fact that there is no condition to be a part of a specific biological species. This helps it to overcome the speciesism argument which is present in those types of definitions. At the same time, the definition stays open to future discoveries of different life forms (extraterrestrial life or artificial intelligence). In addition to moral subject (agent), ethics of social consequences distinguishes moral object which is defined much more widely. All human beings, also animals to some extent, and even the entire universe can potentially be the object of our moral interest and actions, therefore - a moral object (Gluchman, 2018, p. xv). Every moral agent (subject) is a moral object in this definition - and as such deserves the protection and respect of others. However, only a few moral objects are sufficient to fulfill the requirements of becoming a moral agent (subject).

Ethics of social consequences comes from the standpoint that the death of a human being is an irreversible loss of what it is, essentially, to be a human (the intellectual-cognitive position). Ethics of social consequences assumes that the set of functions controlled by the brain are more essential "than a mere pump and set of tubes through which blood flows" (Veatch \& Ross, 2016, p. 6). Ethics of social consequences comes from the position that this definition of what is essential to human existence is based not only on philosophical beliefs. It is based on contemporary medical knowledge and in part on basic religious beliefs as well.

There is a clear difference between a moral agent (subject) and a moral object. This distinction can be identified by the presence of consciousness, rationality, and selfdetermination of the agent and their absence in the moral object. Those attributes are important because they are a prerequisite for the ability which distinguishes (qualitatively) a moral agent from any other being. The distinction is based on the ability of moral responsibility. Moral responsibility in ethics of social consequences is understood as the ability of an agent to take account for his/her actions or omissions. This competence is interconnected with the possibility to praise or blame him/her (reward or punish him/her). However, this understanding is not sufficient enough; additionally, the agent must be able not only to bear something (to take account) but also able to act. On the one hand, the responsibility is understood as the ability to bear, on the other, as the ability to act. It is important to acknowledge this aspect of responsibility: as a facility to assign duties to an agent. The agent must be able to act on behalf of something. If the agent is not capable of acting on behalf of something, it is impossible to refer to him/her as responsible and therefore as an agent; there is no purpose in assigning duties to somebody who is unable to be accountable for them. In this sense, responsibility is understood as an integral and central attribute of moral agency (Kalajtzidis, 2018a).

There are three conditions that must be fulfilled when we want to ascribe moral responsibility to the moral agent and hold him/her responsible. The agent must be confronted with a situation which is morally relevant. He/she must face a morally significant choice involving the possibility of doing something good or bad (right or wrong). The second condition is that he/she is able to judge the situation. The moral agent must be able to acquire relevant information to make a judgment. They must be in a position to see what is (was) at stake. The third condition is to be able to take charge of the way he/she shapes his/her judgment; he/she must be able to choose on the basis of judgment. The choice must be within the domain of the agent's will

\footnotetext{
12 The definition of moral agent used in ethics of social consequences is based on intellectual-cognitive assumptions.

${ }^{13}$ The list comes from Joseph Fletcher article Indicators of Humanhood: A Tentative Profile of Man (1972) and is even used in the bioethics today (e.g. Singer, 2011).
} 
(control) (Kalajtzidis, 2018a). If a person is unable to fulfill those criteria, they cannot relate to the notion of moral responsibility and as such could not be labelled as a moral agent. In this sense, the person cannot be held accountable and is not eligible for moral evaluation. Without this ability, there is no point in reflecting on other aspects of responsibility such as the notion of duty ${ }^{14}$ and notion of guarantee. ${ }^{15} 16$

\section{Wrongness of taking a life?}

Peter Singer lists four possible reasons for maintaining that it is especially serious to take a person's life. In the context of the paper, they can be understood as reasons for maintaining that it is especially serious to take a moral agent's life. Singer includes hedonistic utilitarian concern with the effect of the killing on others; preference utilitarian concern with the frustration of the victim's desires and plans for the future; the right to life and respect for autonomy (Singer, 2011, p. 84).

In a very simplified and brief way, I will try to introduce those reasons in the context of our understanding of life. Utilitarianism judges actions by their tendency to maximize pleasure or happiness and minimize pain or unhappiness. The wrongness of killing a moral agent in utilitarianism lies in the fear that people like myself with a future and desires are sometimes killed. That makes me worry all the time and can make my life less enjoyable. Even though this argument is very odd from a common-sense morality standpoint, this indirect argument is the soundest one from the utilitarian point of view. If we accept euthanasia as a common practice, moral agents might live an anxious life in the fear that their life might be terminated and, in this sense, less filled with pleasure and happiness. It must be understood that this argumentation is only solid with moral agents as they were defined above because only they are able to have a sense of the future. It does not affect moral object as they do not have a sense of the future and therefore cannot have the same worries (which lessen their happiness and pleasure) as moral agents.

Preference utilitarian reason against killing a moral agent is similar to the previous one in focusing on the future. Preference utilitarianism judges actions not by their tendency to maximize pleasure (happiness) or minimize pain (unhappiness), but by the extent to which they agree with the preferences of beings affected by actions or its consequences. According to the argumentation of preference utilitarianism, an action contrary to the preference of any being is, unless this preference is outweighed by contrary preferences, wrong (Singer, 1993, p. 94). Killing a moral agent who prefers to continue living is considered wrong, other things being equal. A moral object might have preferences as well, such as a preference not to suffer, but it is only a moral agent whose death will violate not just one but a wide range of preferences which are connected with future existence (plans, goals, etc...).

The classical version of utilitarianism, as well as the preference version of the theory, do present arguments against the taking of life. As can be seen, both versions of argumentation do support the distinction of life forms and their arguments can hold when applied to moral agents, but not so much to moral objects. The third line of reasoning against taking a life comes from the proponents of the argument based on rights. The idea is a very simple one and it accentuates that we do have a right to life (as a distinct life form). Not every living being does have a right

\footnotetext{
${ }^{14}$ Connected in ethics of social consequences with the ability to make deliberate decisions and act on them. To act in compliance with fundamental moral values, such as human dignity and humanity.

${ }^{15}$ Connected in ethics of social consequences with the ability to bear consequences. To allow (for) the possibility to impute reward or punishment on a moral agent.

${ }^{16}$ It must be stated that the issues of moral responsibility and moral agency are inseparable. Without moral agency, there would be no moral responsibility. Without moral responsibility there would be no moral agency (notion of a moral agent) as we know it. For better understanding of the notion of moral responsibility in ethics of social consequences, see Responsibility and justice: secondary values in ethics of social consequences (Kalajtzidis, 2018a)
} 
to life, or at least it is not strong in the same way as the one of humans. Otherwise, we would be forbidden to eat any kind of meat which comes from living animals, and maybe even plants' right to life should be considered. That is why philosophers look for the way to specify those who do have a right to life ${ }^{17}$ which is considered sometimes even absolute. One of the most used arguments in this notion is, again, connected with the future, more precisely with the ability to plan and anticipate one's future. ${ }^{18}$ Michael Tooley argues that we do have a right to life, which is based on our capacity to desire - what we desire most is a continuing existence (Tooley, 1988, pp. 83-114). Once again, the capacity to desire is limited to those living forms which we referred to in the previous text as a moral agent.

The fourth reason is respect for autonomy. Establishment of autonomy as a basic moral principle is connected with Immanuel Kant, but today strongly present in bioethical literature thanks to principlism. In the understanding of Beauchamp and Childress, autonomy as a principle primarily expresses the possibility of free acting in accordance with our own aims (Beauchamp \& Childress, 2009, pp. 99-100). Taking the life of a person who does not choose to die is considered to be the most serious violation of the person's autonomy. The question which arises is, if the moral object, as it was defined in the text, is suitable for attribution of autonomy. If we take into account that free acting in accordance with our own aims is required then the autonomy stays reserved for the moral subjects only.

\section{Ethics of social consequences and euthanasia}

As Wendy Drozenova notices in her article on euthanasia, it is well known that disagreement in the moral evaluation of behaviour is often due to a disagreement in knowledge of facts (not moral principles) (Drozenová, 2013, p. 63). That is why we are now going to look closer at the issue of euthanasia in the understanding of ethics of social consequences.

If we accept the definition of euthanasia which comes from Beauchamp and Davidson, it is important to concentrate on a few fundamental issues when we look for clarification. 1) It is possible to talk about euthanasia only when the human being/ person/ moral agent is at stake. ${ }^{19}$ 2) Death is intended by at least one other moral agent. 3) The aim of the act is to relieve the one who is either suffering or irreversible comatose (benefit for the one killed). 4) the method used must be on behalf of the agent.

In the literature, we distinguish three basic types of euthanasia - voluntary, involuntary and non-voluntary. The voluntary form is, in connection to the mentioned issues, the least problematic. When the moral agent is mentally competent and adequately informed, I believe there are no moral restrictions that could forbid him/her from making a decision about euthanasia. The voluntary request of a moral agent (if in compliance with any medical conditions which are set) should not be violated. The same applies to a former moral subject who consented before he/she became a moral object.

The involuntary form of euthanasia appears to be much more peculiar. Involuntary euthanasia is defined as one in which a person possesses the capacity to agree or disagree but has not provided consent. This happens either because they are not asked, or because they are asked and choose to go on living. I believe that this type of "euthanasia" does not exist or exists only in a very bizarre theoretical situation. This type of "euthanasia" does not support the abovementioned conditions (e. g. neither number 3 nor 4) from the definition used. It can be claimed

\footnotetext{
${ }^{17}$ What properties must a thing possess in order to have a right to life? This is a most tricky question in the connection to the right to life argumentation.

${ }^{18}$ Death, dying, euthanasia and many other similar issues should be understood in their complexity. The life of the moral agent has many different aspects such as psychological, sociocultural, spiritual and other. The spiritual aspect can be understood through moral and aesthetic emotions which are considered to be higher emotions. In synergy, they help us to generate notions of our past and future to create goals and ideas in our life (Makky, 2019). ${ }_{19}$ The being whose life is at stake can possibly be a moral object, but there is a requirement that they had been a moral agent in the past.
} 
that this type of life-ending should be labelled as something other than euthanasia (in some cases probably even murder).

Non-voluntary euthanasia is the one that is the most problematic. The paper accepts the definition of non-voluntary euthanasia as that which occurs when the person concerned has been unable to express an opinion, usually because they lacks the capacity to do so (Biggs, 2001, p. 12). Another important condition is that the person to whom it relates previously has not requested or rejected euthanasia in these circumstances. If they requested euthanasia (as a moral agent in the past) then it can be labelled as voluntary euthanasia (from the point of view of our previous argumentation). Therefore, non-voluntary euthanasia should involve the killing of a moral object who never was a moral subject, or one which was a moral subject before, but as one, they never requested or rejected euthanasia in these circumstances. However, this type of description does not correspond with the first requirement of the definition of euthanasia, which demands that when we talk about euthanasia, we should have in mind a moral agent or former moral agent.

If we were to try to overcome the problematic first requirement, the consequences could be very odd. The circumstances would allow us to see the death of an animal (which is considered a moral object) or any living being as a case of euthanasia. Abortion as well as the killing of an animal for dinner would be considered euthanasia. We can soften the requirement and consider replacing it with a different request such as: The being whose life is at stake could possibly be a moral object, but there is a precondition (to overcome the former insufficiency) that they had been a moral agent in the past. Although, in this case, a new issue arises. What should we do with severely damaged humans who were born as a moral object without any potential to become a moral subject? Is it even possible to talk about euthanasia in their case? If yes, what kind of euthanasia? It would probably be wrong to dismiss severely damaged humans and other moral objects from the discussion on euthanasia. In this case, it might be useful to look at the issue from a different point of view. Not from the perspective of the object of euthanasia (and even admit that euthanasia also exists in the connection with animals and unborn beings) but from the perspective of the aim of killing (benefit for the being killed). In that case, we should change the first condition to: Is it possible to talk about euthanasia when the life of a moral object or a moral subject is at stake. The requirement (footnote number 16) that the moral object must have been a moral subject should, then, be revoked. ${ }^{20}$

So-called voluntary euthanasia will stay reserved for a mentally competent and adequately informed moral subject or a former moral subject who, when he/she was able to do so, requested euthanasia in these circumstances. Involuntary euthanasia will stay ungrounded and nonvoluntary euthanasia will be used when moral objects are the case. A moral object who was never a moral subject or one which was a moral subject before, but as one, they never requested or rejected euthanasia in these circumstances.

\section{Conclusion}

From the point of view of ethics of social consequences, it is not only voluntary euthanasia which seems to be without any significant issues. Even non-voluntary euthanasia in the context of the paper and the theory is not that as uncertain as many people might think. As was mentioned, non-voluntary euthanasia could be performed in two different cases. Moral objects who were never a moral subject and moral objects who were moral subject but did not give a clear answer to the question of euthanasia.

In my previous paper (Kalajtzidis, 2018b), I distinguished between the death of a person and the death of an organism and agreed that it is our mind that makes us who we are. We persist

\footnotetext{
${ }^{20}$ What is important is to adhere to condition number 3 from the definition: The aim of the act is to relieve the one who is either suffering or irreversibly comatose (benefit for the one killed). If the condition is fulfilled, then my previous notes about abortion and animal killing are irrelevant.
} 
as long as our mind remains intact. When a being has lost its ability to be a moral agent, it dies as a person. However, the human being still exists and is labelled a moral object. The person (moral agent) is dead, but the body survives (moral object). The question which stands in front of us will be whether these living bodies (moral objects) that are no longer moral agents (persons) should be treated differently from normal living people (moral subjects) in the case of euthanasia. Ethics of social consequences would answer positively. ${ }^{21}$

As was already shown in the previous part - wrongness of taking a life? - the four reasons which were mentioned do not really apply to our case of moral objects. As they do not have a sense of the future, they can be neither affected by hedonistic nor preference utilitarianism arguments. We argued that the capacity to desire as a prerequisite to the right to life is once again limited to those living forms which were labelled as moral agents. In the same way, the argument on respect for autonomy was dismissed on the grounds of the unfeasibility of moral objects to act freely in accordance with their own aims. Moreover, as was already mentioned, death is considered bad mostly because it deprives us of the good things we would enjoy had we lived on. As the definition of moral object states, it is clearly impossible for moral objects to enjoy life as they only "are" as living entities and do not really exist as active beings.

I believe the same applies to both cases of non-voluntary euthanasia. As in the light of the presented understanding, it does not matter if a moral object who was a moral subject did or did not request euthanasia, as their wish does not matter anymore. ${ }^{22}$ What could matter is a clear rejection (during a state of moral agency) as it might be important for other moral agents to keep the promise/ wish. Not in the matter of pure wish/ promise keeping, but in the matter of arguments mentioned in the part wrongness of taking a life? as performing unwanted euthanasia might lower the potential quantity of happiness because we would worry that it might happen to us. What should be done in those cases I do not dare to say (for now).

\section{References}

BEAUCHAMP, T. L. \& CHILDRESS, J. F. (2009): The principles of biomedical ethics. Oxford: Oxford University Press.

BEAUCHAMP, T. L. \& DAVIDSON, A. I. (1979): The definition of euthanasia. In: The Journal of Medicine and Philosophy, 4(3), pp. 294-312.

BIGGS, H. (2001): Euthanasia, death with dignity and the law. Canterbury: Hart Publishing. DROZENOVÁ, W. (2013): Otázka legalizace eutanazie v ČR z pohledu systémového hodnocení sociálních změn [The question of legalization of euthanasia in the Czech Republic from the point of view of systemic evaluation of social changes]. In: D. Černý \& A. Doležal (eds.): Smrt a umírání. Etické, právní a medicinské otazníky na konci života [Death and dying: Ethical, legal and medical questions at the end of life]. Praha: Ústav státu a práva AV ČR, pp. 61-75.

FLETCHER, J. (1972): Indicators of humanhood: A tentative profile of man. In: The Hastings center Report, 2(5), pp. 1-4.

GLUCHMAN, V. (2018): Introduction: Ethics of social consequences - the past and the present. In: V. Gluchman (ed.): Ethics of social consequences: Philosophical, applied and professional challenges. Newcastle upon Tyne: Cambridge Scholars Publishing, pp. viii-xxvii. GLUCHMAN, V. (2009): Dignity and human dignity as a methodological basis of bioethics. In: V. Gluchman (ed.): Bioethics in Central Europe: Methodology and education. Prešov: FF PU, pp. 73-86.

\footnotetext{
${ }^{21}$ There are two basic arguments for this position. The first is the already mentioned value structure of the theory which is connected to the protection and support of life. The second is the consequential attitude of ethics of social consequences. For precise argumentation, I suggest my previous paper (Kalajtzidis, 2018b).

${ }^{22}$ As their, or other moral objects, cannot be influenced by that.
} 
GLUCHMAN, V. (1999): Etika sociálnych dôsledkov v kontexte jej kritiky [Ethics of social consequences in the context of its critique]. Prešov: L.I.M.

GLUCHMAN, V. (1997): Človek a morálka [Person and morality]. Brno: Doplněk.

GLUCHMAN, V. (1994): Angažovanost', solidarita, zodpovednost' [Involvement, solidarity, responsibility]. Prešov: Universum.

KALAJTZIDIS, J. (2018a): Responsibility and justice: Secondary values in ethics of social consequences. In: V. Gluchman (ed.): Ethics of social consequences: Philosophical, applied and professional challenges. Newcastle upon Tyne: Cambridge Scholars Publishing, pp. 2-23. KALAJTZIDIS, J. (2018b): The challenge of death and ethics of social consequences: Death of moral agency. In: Ethics \& Bioethics (in Central Europe), 8(3-4), pp. 209-218.

KOMENSKÁ, K. (2018): Death, ethical judgments, and dignity. In: Ethics \& Bioethics (in Central Europe), 8(3-4), pp. 201-208.

MAKKY, L. (2019): Od začiatku po koniec a ešte d'alej: umenie v definičných súradniciach [From the beginning to the end and beyond: Art in the definition coordinates]. Prešov: FF PU. SINGER, P. (2011): Practical ethics. Cambridge: Cambridge University Press.

SINGER, P. (1993): Practical ethics. Cambridge: Cambridge University Press.

TOOLEY, M. (1988): In defense of abortion and infanticide. In: M. F. Goodman (ed.): What is a person. New Jersey: The Humana Press, pp. 83-114.

VEATCH, M. R. \& ROSS, L. F. (2016): Defining death: The case for choice. Washington, DC: Georgetown University Press. 